DOI 10.37882/2223-2982.2020.11.09

\title{
ПРЕПОДАВАНИЕ ИСПАНСКОГО ЯЗЫКА КАК ИНОСТРАННОГО В РЕЖИМЕ ОНЛАЙН
}

\section{TEACHING SPANISH AS A FOREIGN LANGUAGE ONLINE}

\section{A. Gorenko \\ J. Karpova \\ E. Terentyeva}

Summary: This article discusses the issues of teaching Spanish as a foreign language online. The effectiveness of the use of computer technologies in the study of the Spanish language is analyzed, as well as the creation of the necessary conditions for the development of students communicative competence. The functions of pedagogical technologies that are supposed to be implemented when teaching Spanish as a foreign language online are described. The Internet resources of publishers engaged in the creation of electronic linguodidactic materials for learning Spanish as a foreign language are investigated. The article identifies the most useful resources that can be used in teaching Spanish as a foreign language online. The results of teaching Spanish as a foreign language online in the context of a pandemic in 2020 are shown. The author comes to the conclusion that the use of computer technology in the process of learning Spanish makes it easier for students to learn it and create a familiar environment for them. Thanks to multimedia resources, the study of the Spanish language can be continued in a pandemic and selfisolation and make it continuous.

Keywords: Internet resources, e-learning, Spanish as a foreign language, publishing, online education in a pandemic, computer programs, electronic sources, online audio and video resources, teaching technology, multimedia resource.
Горенко Анна Александровна

К.филол.н., доцент, Московский государственный институт международных отношений

(Университет) МИД РФ belanna_77@mail.ru

Карпова Юлия Анатольевна

К.филол.н., дочент, Московский государственный университет имени М.В. Ломоносова karpovamsu@gmail.com

Терентьева Екатерина Дмитриевна К.филол.н., дочент, Российский университет дружбы народов (Москва) terentyeva-ed@rudn.ru

Аннотация: В настоящей статье рассматриваются вопросы преподавания испанского языка как иностранного в режиме онлайн. Анализируется эффективность использования компьютерной технологий при изучении испанского языка, а также создание необходимых условий для развития коммуникативной компетенции студентов. Описываются функции педагогических технологий, которые предполагается реализовать при преподавании испанского языка как иностранного в режиме онлайн. Исследуются интернет-ресурсы издательств, занимающихся созданием электронных лингводидактических материалов для изучения испанского языка как иностранного. Выявлены наиболее полезные ресурсы, которые могут быть использованы при преподавании испанского языка как иностранного в режиме онлайн. Показаны результаты преподавания испанского как иностранного в режиме онлайн в условиях пандемии в 2020 году. Автор приходит к выводу, что использование компьютерных технологий в процессе изучения испанского языка позволяет облегчить процесс его освоения для студентов и создать привычную для них среду. Благодаря мультимедийным ресурсам изучение испанского языка можно продолжить в условиях пандемии и самоизоляции и сделать его непрерывным.

Ключевые слова: интернет-ресурсы, электронное обучение, испанский язык как иностранный, издательство, онлайн обучение в условиях пандемии, компьютерные программы, электронные источники, онлайн аудио и видео ресурсы, технология преподавания, мультимедийный ресурс.

вания приобретают новый формат $[1,2,3]$.

Онлайн-занятия по испанскому языку показали овладение новым опытом взаимодействия преподавателя и учащихся, развитие творческого мышления, возможность самосовершенствования, принятия нравственных норм и правил совместной деятельности [4].

При преподавании испанского языка как иностранного в режиме онлайн используются электронные материалы и технические средства: смартфоны, планшеты, ноутбуки, компьютеры и доступ к Интернету. Все необходимые задания размещаются в личном кабинете си- 
стемы дистанционного обучения. Учащиеся выполняют задания на специальной веб-платформе учебного заведения.

Система онлайн обучения позволяет решить следующие задачи (рисунок 1).

Отметим, что преподавание испанского языка как иностранного в режиме онлайн имеет свою специфику. Так, чтобы удерживать интерес и мотивацию учащихся, необходимо, чтобы студенты имели возможность переключаться на разные задачи или задания, оставались вовлеченными в процесс обучения. Однако, онлайн обучение имеет и минусы - длительное нахождение у компьютера, что может отразиться на состоянии здоровья студентов и преподавателей.

Педагогические технологии при преподавании испанского языка как иностранного в режиме онлайн помогают реализовать следующие функции (рисунок 2) [5].

Рассмотрим наиболее известные интернет-ресурсы издательств, создающих лингводидактические материалы для изучения и преподавания испанского языка как иностранного в режиме онлайн.

Согласно наиболее крупному сайту для подготовки преподавателей profesoresdeele.org [6] в списке издательств, разрабатывающих и издающих материалы для изучающих испанский язык в качестве иностранного (ELE - Español como lengua extranjera), обозначено 26 издательств. Другой крупный портал, посвященный изучению испанского языка, - todoele.net [7] содержит альтернативный список издательств, включающий в себя 30 позиций.

Нами проведен анализ сайтов 15 мировых издательств, выпускающих литературу для изучения и преподавания испанского языка в качестве иностранного, а именно: Difusión, ELI Publishing, EnClave ELE, Habla con Eñe, Hispania Línguas Latinas, Houghton Mifflin Harcourt, Octaedro ELE, Pearson, Pons, Santillana ELE, Santillana Brasil, SGEL ELE, SM Español para Extranjeros, Vista Higher Learning, Voces del Sur. В результате данного анализа мы пришли к следующим выводам.

Издательство SM Español para Extranjeros предоставляет дополнительные электронные материалы к серии учебников Protagonistas (A1-B2) и Aprueba el DELE (A1A2). Так, вместе с классическими аудио- и видеозаписями предлагается новый инструмент - онлайн-тетрадь, доступ к которой осуществляется на сайте после ввода пароля [8].

Компания Vista Higher Learning предлагает онлайнкурс испанского Portales, разработанный специально для преподавателей, чтобы помочь им организовать собственный курс из 18 уроков [9]. Этот инструмент платный и по своему функционалу похож на подобные решения в сфере интернет-образования, такие как Rosetta Stone.

У одного из самых узнаваемых и влиятельных издательств SGEL ELE есть свой вебсайт для курса общего испанского Agencia ELE [10], где в дополнение к основным учебным материалам представлены интерактивные упражнения. Среди преимуществ данных упражнений можно отметить следующие (рисунок 3).

К недостаткам данного ресурса можно отнести то, что, начиная с уровня В1.2, задания прекращают быть интерактивными, а охват тем ограничен главами учебника, то есть не предполагает регулярного внесения дополнений и обновлений.

Издательство Santillana Español разработало свой собственный образовательный портал, доступ в который предоставляется по подписке, вместе с тем некоторые ресурсы имеются в открытом доступе. Портал предлагает девять различных сервисов (рисунок 4) [11].

Santillana ELE, издательство при Университете Саламанки, входящее в группу PRISA, предлагает на своем сайте доступ к определенным ресурсам, в основном выдержкам из различных учебников издательства [12].

Издательство PONS предлагает ряд электронных словарей и методических материалов по изучению испанского, приложения с испано-итальянским словарем [13].

Habla con Eñe предлагает онлайн-курс испанского языка Habla с подпиской на 1 месяц, 4 месяца и 1 год для уровней A1, A2 и В1. Часть мультимедийных материалов данного курса, а также озвученные тексты с глоссарием и частично упражнениями представлены в открытом доступе на портале Habla Cultura [14]. Часть текстов на данном портале взята из журнала Punto у Coma [15], который выпускается издательством Habla con Eñe в печатном и электронном форматах 6 раз в год. Все статьи в представленном журнале озвучены, дополнены глоссарием и упражнениями формата международного экзамена DELE и нацелены на студентов уровня В1 и выше.

Компания EnClave ELE предоставляет дополнительные электронные материалы ко всем своим учебникам, доступ к которым ограничен кодом. Помимо этого, издательство разработало свою виртуальную библиотеку [16], где выложена часть аудио- и видеоматериалов, информация о вебинарах и конференциях для преподавателей.

Hispania Línguas Latinas - школа испанского и португальского языка в Сан-Паулу, предлагает свой онлайн- 
1. Хранить электронные учебники, учебные пособия, видеоролики и другой учебный контент. Студенты могут в любое удобное время зайти на портал и изучить нужный материал.

2. Получать практические навыки: проектные задания практикумы, проверочные работы, написание эссе, участие в веб-конференциях, в веб-дебатах, проводить персональые консультации, назначать задания группе или индивидуально студенту.

3. Тестировать: тесты различньг форм позволяют контролировать и координировать усвоение и успеваемость, интернет-олимпиады и др.

4. Контролировать качество обучения. По размещённому материалу в системе онлайн образования можно получить детальню статистику, а именно: какие материалы изучают студенты, какой балл набрали в тестах. С ее помощью удобно контролировать уровень подготовки студентов и оценивать их успеваемость.

Рис. 1. Задачи, решаемые системой онлайн обучения

- формирование умений и навыков самостоятельной работы;

- развитие навыков урегулирования конфликтов;

- обучение ведению бесконфликтного дискурса;

- самостоятельный контроль приобретенньх знаний;

- ориентация на овладение испанским языком как средством профессионального общения;

- стремление к непрерьвному совершенствованию нспанского языка;

- порождение аргументации и исследоват елского понска решения проблемы;

- наличие проблемньх ситуаций, способствующих развитию творческого и критического мьшления и умениям цивилизованной аргументации

Рис. 2. Функции, которые помогают реализовать педагогические технологии при преподавании испанского языка как иностранного в режиме онлайн 
1. Материалы разбиты по темам. К каждой теме дается ссылка на конкретную главу учебника Agencia ELE.

2. Есть возможность моментально проверить ответы и при необходимости пройти задание еще раз.

3. Предлагается пять видов заданий: социокультурный тест, расставление фраз в диалоге с последующей возможностью его прослушать и исправить при необходимости, грамматическое задание на раскрытие скобок в тексте, соединение фраз, кроссворд с прослушиванием контекста испольования ключевого слова. Разработчиками предусмотрены самые разнообразные варнацин в рамках этнх пяти вндов заданий.

4. Все задания находятся в открытом доступе.

Рис. 3. Преимущества интерактивных упражнений, размещенных на сайте издательства SGEL ELE

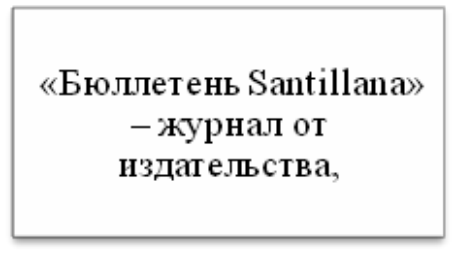

генератор "Sopas de letras" (поле с буквами, где нужно найти слова),

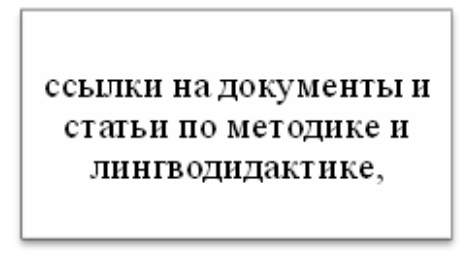

грамматикав презентациях PowerPoint,
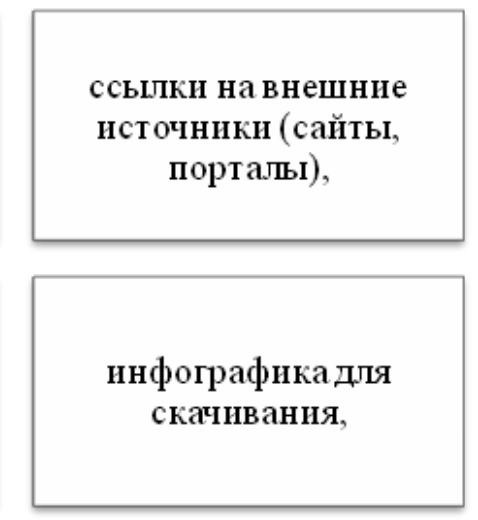
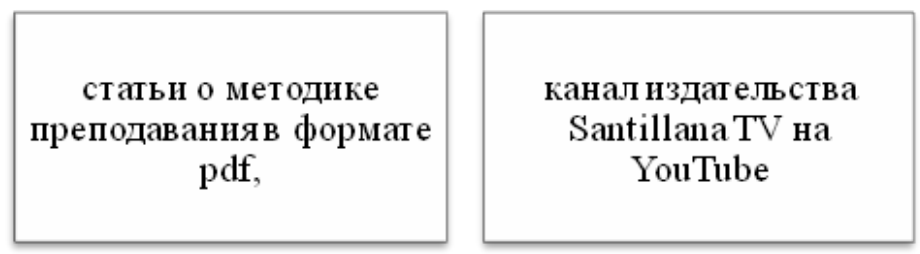

Рис. 4. Сервисы образовательного портала издательства Santillana Español

курс обучения испанскому [17].

Издательство Difusión имеет собственную цифровую платформу Campus Difusión [18], где представлены материалы как для студентов, так и для преподавателей. Более 150 видео с субтитрами и упражнениями, презентации грамматического материала, аудио, задания, основанные на актуальных новостях, картинки и кар- точки для коммуникативных заданий, более 2000 интерактивных упражнений, электронные книги, экзамены и вебинары - все перечисленные материалы, дополняемые каждый месяц, доступны студентам и преподавателям по подписке на 1 месяц или 1 год. Предоставляется возможность бесплатно зарегистрироваться и работать с материалами для бесплатного пользования. Отдельно стоит подчеркнуть, что Difusión - единственное изда- 
тельство, разработавшее для своей платформы приложение для планшетов и смартфонов.

Проведенный нами анализ интернет-ресурсов издательств, занимающихся созданием электронных лингводидактических материалов для изучения испанского языка как иностранного позволяет прийти к выводу, что явными лидерами в предоставлении онлайн-ресурсов для изучения и преподавания испанского языка как иностранного являются портал Campus Difusión от издательства Difusión и сайт Agencia ELE от издательства SGEL ELE. Тем не менее последний представляет собой лишь набор комплементарных онлайн-упражнений к главам одноименного учебника, что накладывает определенные ограничения на содержание и наполняемость сайта. Более того, ресурс Agencia ELE не содержит отдельных дидактических материалов для преподавателей.

Для преподавания испанского как иностранного в режиме онлайн в условиях пандемии подходят социальные сети (Instagram, Facebook, ВКонтакте и т.д.) где можно создать свою страницу и выкладывать материалы по теории и практике, видео и аудиоматериалы, вести прямую трансляцию с объяснением материала.

Для осуществления обратной связи, проведения онлайн занятий можно использовать телекоммуникационные сервисы Skype, WhatsApp, Zoom.

Преподавание испанского как иностранного в режиме онлайн в условиях пандемии в 2020 году показало следующие результаты:

1. Экранная культура требует особых условий для ее реализации в обучении. Во-первых, задействованными оказываются только два анализатора: слуховой и визуальный. Оба достаточно напряжены в течение длительного промежутка времени. В оставшееся время они также остаются в условиях самоизоляции перегруженными. Все это очень быстро приводит к хронической усталости и преподавателей, и обучающихся. Во-вторых, абсолютно исчезает из процесса обучения его субъектнодеятельностный компонент. Это сильно обедняет процесс обучения испанскому языку.

2. В связи со сниженной двигательной активностью возрастает мышечная усталость и обучающихся, и преподавателей. В дистанционном обучении начинает превалировать самостоятельная работа, превращающая его в заочное обучение. Объемные задания, сроки их выполнения, условия сдачи подчинены общему учебному графику и ритму обычного учебного дня. В удаленном формате реальный день обучающихся складывается следующим образом. Первую половину дня они проводят у экрана, слушая преподавателей, вто- рую - сидят у тех же экранов мониторов, выполняя домашние задания. Преподаватели проходят тот же путь: первую половину дня ведут занятия, вторую - готовятся к следующей встрече и проверяют выполненные задания.

3. Геолокационная доступность обучения испанскому языку как иностранному. Например, преподаватели и обучающиеся могут находиться на даче и одновременно без всяких проблем проводить и посещать учебные занятия, не тратя время на дорогу и уменьшая таким образом риск заражения. Территориальная независимость подразумевает выход и за границы отечественного образования. Многие зарубежные университеты, в том числе испанские языковые школы, предлагают и транслируют уникальные лекции ведущих специалистов, которые можно посещать в свободном доступе.

4. Возможно расширение персональной доступности обучению испанскому языку как иностранному. В него могут включаться и лица без ограничений физического здоровья, и люди с ограниченными его возможностями и инвалидностью. Оно удобно для соматически больных учащихся, находящихся на длительном лечении.

5. Однообразный фон и небогатые методы преподавания испанского языка как иностранного онлайн, его обедненная эмоциональность вызывают отторжение у экстравертов.

6. При завершении начального этапа внедрения онлайн обучения испанскому языку, налаживания технического оснащения возрастает вероятность перехода вуза на интенсивный образовательный путь вместо экстенсивного. Появляется возможность проводить занятия в формате конференций, вебинаров, реальных дискуссий между студентами разных групп и даже разных вузов. В дальнейшем возможна осмысленная и разумная комбинация аудиторных занятий с дистанционным обучением, привлечение для единичных онлайн-встреч крупнейших специалистов, в том числе из Испании и пр.

Таким образом, преподавание испанского как иностранного в режиме онлайн в условиях пандемии имеет как положительные стороны, так и отрицательные. Однако, большим преимуществом является то, что используемые новые педагогические электронные технологии при преподавании испанского как иностранного на онлайн-занятиях, помогает студентам продолжить образование и защитить себя от коронавирусной инфекции. Использование компьютерных технологий в процессе изучения испанского языка позволяет облегчить процесс его освоения для студентов и создать привычную для них среду. 
В заключение отметим, что развитие необходимых компетенций у студентов, изучающих испанский язык как иностранный в условиях пандемии невозможно без использования интернет-технологий, которые необходимо совершенствовать и развивать. Ответственность за развитие данных технологий лежит на плечах не только преподавателей и учебных заведений, но и издательств.

Поэтому задача издательств состоит не только в создании и обновлении дидактических материалов в электронном формате, но и в разработке онлайн-ресурсов, которые могут стать эффективным инструментом в деятельности современного преподавателя и студента. Одновременно задача вузов и преподавателей - поиск путей сотрудничества с издательствами для создания интернет-ресурсов, отвечающих требованиям программы изучения испанского языка как иностранного и обладающих необходимым инструментарием ведения группы и контроля.

\section{ЛИТЕРАТУРА}

1. Ковынева И.А. Профессиональная компетентность как важный фактор в подготовке преподавателя высшей школы / В сборнике: Традиционные и инновационные подходы к модернизации медицинского образования. Печатается по решению редакционно-издательского совета Государственное образовательное учреждение высшего профессионального образования «Курский государственный медицинский университет Федерального агентства по здравоохранению и социальному развитию». 2010. С. 194-196

2. Ковынева И.А., Петрова Н.Э. Интеграционные процессы в высшей школе РФ: инновационные подходы в системе РКИ / В сборнике: Образовательный процесс: поиск эффективных форм и механизмов Сборник трудов Всероссийской научно-учебной конференции с международным участием, посвященной 82-й годовщине КГМУ. Под редакцией В.А. Лазаренко, П.В. Калуцкого, П.В. Ткаченко, А.И. Овод, Н.Б. Дрёмовой, Н.С. Степашова. 2017. С. 289-293

3. Терентьева Е.Д., Горенко А.А., Карпова Ю.А. Возможности использования официальных интернет-ресурсов в процессе самостоятельной работы студентов при обучении испанскому языку // Современная наука: актуальные проблемы теории и практики. Серия: Гуманитарный науки. 2020. №6. С. 183-186

4. Лешутина И.А. Активизация возможностей личности и коллектива как залог эффективного обучения РКИ / В сборнике: Методика преподавания иностранных языков: традиции и инновации Сборник научных трудов по материалам международной научно-методической конференции-вебинара: В 2-х частях. 2016. С. 291-295

5. Наджафов И.А. Педагогические технологии онлайн-обучения иностранному языку, защищающие студентов в период коронавирусной инфекции // Методика преподавания иностранных языков и РКИ: традиции и инновации : сб. науч. тр. V Междунар. научно-метод. онлайн-конф. (14 мая 2020 г.). Курск : Изд-во КГМУ, 2020. - С.133-137

6. Enseñar Español como lengua extranjera [Электронный ресурc]. URL: http://profesoresdeele.org/editoriales-de-ele/ (дата обращения: 28.08.2020)

7. Todoele.net [Электронный ресурс]. URL: http://www.todoele.net/editoriales/Editoriale_list.asp?EditorialesPage=1 (дата 0бращения: 28.08.2020)

8. SM Español para Extranjeros [Электронный ресурc]. URL: http://www.sm-ele.com/ver_galeria_enlaces.aspx?id=18444 (дата 0бращения: 28.08.2020)

9. Vista Higher Learning [Электронный ресурс]. URL: http://vistahigherlearning.com/portales/ (дата обращения: 28.08.2020)

10. Agencia ELE [Электронный ресурc]. URL: http://www.agenciaele.com/ (дата обращения: 28.08.2020)

11. Santillana Español [Электронный ресурc]. URL: http://www2.richmond.com.br/vestibulares/santillana/ (дата обращения: 28.08.2020)

12. Santillana ELE [Электронный ресурc]. URL: http://www.santillanaele.com/recursos (дата обращения: 28.08.2020)

13. PONS idiomas [Электронный ресурc]. URL: https://ponsidiomas.com/etiqueta-producto/espanol/ (дата обращения: 28.08.2020)

14. Habla Cultura [Электронный ресурc]. URL: https://hablacultura.com (дата обращения: 28.08.2020)

15. Punto y Coma [Электронный ресурc]. URL: https://hablaconene.com/inicio/revista-punto-y-coma (дата обращения: 28.08.2020)

16. EnClave ELE [Электронный ресурc]. URL: http://enclave-ele.weebly.com/ (дата обращения: 28.08.2020)

17. Hispania Línguas Latinas [Электронный ресурc]. URL: http://www.hispanialinguas.com.br/espanhol\%20online.htm (дата 0бращения: 28.08.2020)

18. Campus Difusión [Электронный ресурc]. URL: https://www.difusion.com/campus (дата обращения: 28.08.2020)

( Горенко Анна Александровна (belanna_77@mail.ru), Карпова Юлия Анатольевна (karpovamsu@gmail.com), Терентьева Екатерина Дмитриевна (terentyeva-ed@rudn.ru).

Журнал «Современная наука: актуальные проблемы теории и практики» 